\title{
LAS COOPERATIVAS DE TRABAJO ASOCIADO EN LA ECONOMÍA DE PLATAFORMAS
}

\author{
Alicia Villalba Sánchez \\ Prof ${ }^{a}$ Ayudante Doctora de Derecho del Trabajo y de la Seguridad Social \\ Universidad de Santiago de Compostela \\ Secretaria del Centro de Estudios Cooperativos \\ Universidad de Santiago de Compostela (CECOOP) \\ https://orcid.org/0000-0001-8188-4810
}

\section{RESUMEN}

De la Cuarta Revolución Industrial han aflorado espacios virtuales donde intercambiar prestaciones de todo tipo. Las de servicios no han permanecido ajenas a este fenómeno, resultando usual encontrar ecosistemas digitales que, merced a una gestión algorítmica, fueron concebidos para organizar e incluso albergar trabajo de todo tipo. Tratándose de un entorno inédito, las relaciones concertadas en su seno han sido poco propensas a la regulación, integrándose en el vago concepto de la "economía colaborativa". La concurrencia en ellas de trazos distintivos de otras conocidas por el ordenamiento jurídico obliga a resolver dicha confusión distinguiendo colaboración de cooperación, con el firme propósito de deslindar el espacio que la cooperativa de trabajo asociado está llamada a ocupar dentro de la economía de plataformas previniendo, a su vez, el uso espurio que de ella pudiera hacerse disimulando otras formas de prestar servicios.

PALABRAS CLAVE: Economía social, economía de plataformas, economía colaborativa, cooperativas de trabajo asociado, trabajo por cuenta ajena, trabajo por cuenta propia, cesión ilegal de trabajadores, Seguridad Social.

CLAVES ECONLIT / ECONLIT DESCRIPTORS: J41, J46, J50, J54, K31, P13.

Cómo citar este artículo/How to cite this article: VILLALBA SÁNCHEZ, Alicia: "Las cooperativas de trabajo asociado en la economía de plataformas", CIRIEC-España, Revista Jurídica de Economía Social y Cooperativa, n³ 38, 2021, pp. 93-125. D0I: 10.7203/CIRIEC-JUR.38.20794 


\section{WORKER COOPERATIVES IN THE PLATFORM ECONOMY}

\section{EXPANDED ABSTRACT}

The relevance acquired by the virtual environment as a meeting point between job seekers and providers of employment is a polymorphous phenomenon of diverse aetiology. Its origin lies in the technological evolution that has made it possible to articulate digital platforms, but its success depended, to a large extent, on an economic situation characterised by the disappearance of companies and the consequent scarcity of jobs. The economic depression that began in 2008 gave an unusual boost to those digital platforms that, instead of channelling the exchange of services between peers, have hosted offers of subordinate employment that often sought to escape from labour discipline. The need to turn to this new environment in search of a job that did not exist in the traditional labour market soon transformed a sphere originally conceived for collaboration between individuals into an environment where initiatives driven by the profit motive prevailed, with hardly any legal restrictions. The collaborative economy is thus distinguished as part of a platform economy where other business models also find a place.

Despite the predatory contracting that has proliferated in the platform economy, it is important not to miss the opportunities that the legal system offers us to make the most of a technological base whose characteristics fit well with the cooperative paradigm. Free membership through open and accessible digital environments; democratic management through the design and application of algorithms by the members themselves; and the autonomy offered by the registration of any acts through distributed and self-managed systems based on the blockchain are three key aspects which allow us to predict a prosperous future for the cooperatives within the so-called "platform economy". Achieving them, however, requires addressing the difficult distinction between "collaborative platforms", "platform cooperativism" and the simple cover-up of bogus self-employment.

A priori, the worker cooperative could be a vehicle for an initiative that provides jobs for its members in accordance with cooperative principles. Although the members' relationship with it is of a corporate nature, article 14 of Royal Legislative Decree 8/2015 of 30 0ctober, which approves the revised text of the General Social Security Act, allows cooperatives to opt in their articles of association to assimilate their worker-members to employees and, therefore, to include them in the General Social Security Scheme; or to include them in the Special Scheme for Self-Employed Workers. The fact that the co-operative offers this possibility, which does not exist in capitalist companies, has attracted the attention of those who wish to use it in a way that is spurious to the inspiring principles of the cooperative movement. 
This happens when a cooperative recruits worker-members to put them at the disposal of other companies without providing them with organisational, material, financial or management structures that allow and facilitate the most efficient provision of self-employment. An illegal transfer is thus consummated, all the more serious when it is carried out under the protection of an entity belonging to the social economy, whose activity is presumed not only to be in accordance with the law, but even beneficial for its members and for the community that hosts it. Or when, without engaging in the illegal lending of workers, they camouflage the pure and simple provision of self-employed work by their members under the umbrella of an entity through which they invoice their services. Reference is made to digital invoicing cooperatives, dedicated to recruiting professionals to whom they offer a tailor-made tax and social security regime. The risk of disguising an illegal transfer of workers under the cooperative form or of making the cooperative a mere intermediary entity for invoicing purposes means that the existence of a real cooperative must be established, a task that has so far been undertaken by case law. It is therefore particularly important to accredit the activity actually carried out by the cooperative in order to ascertain that this demonstrates the effective creation and organisation of mechanisms for internal action and relations with clients which result in the provision of common services, generating and promoting business management formulas, whether in the purely material sphere, advice, cost reduction, attracting clients, or any other type which results in the better development of the provision of services to its members.

Since art. 7 of the ILO Recommendation no. 193 (2002) on the promotion of cooperatives warns the signatories of the need to "ensure that cooperatives cannot be created or used to evade labour legislation", it is essential to ensure that its constitution "does not serve to establish disguised employment relationships". This purpose can only be achieved by fighting "against pseudo-cooperatives, which violate workers' rights". In this regard, it is considered appropriate, firstly, to elucidate the role that the worker cooperative is called upon to play in the so-called "platform economy", differentiating it from initiatives motivated by an altruistic purpose, but also from those that conceal real salaried work. And, secondly, to propose possible methods to prevent it from being used to subvert the principles of the social economy. This will be helped by the legal reform by virtue of which the activity of persons providing paid services consisting of the delivery or distribution of any consumer product or commodity, by employers who exercise the entrepreneurial powers of organisation, direction and control directly, indirectly or implicitly, by means of algorithmic management of the service or working conditions, through a digital platform. Finally, various measures are proposed to promote the development of platform cooperativism as an alternative way of benefiting not only economically but also socially from the platform economy. Specifically, it stresses the need to adopt measures to provide financial support and technical advice to those who dare to set up a worker cooperative in this digital ecosystem. However, insofar as 
their development requires the acquisition of legal and economic knowledge about the social economy, in general, and about the cooperativism, in particular, it is essential to strengthen the role that educational institutions are called upon to play in promoting them. In this way, graduates will have the necessary tools to successfully undertake a cooperative project in a context once again marked by the economic decline resulting from the current pandemic.

KEYWORDS: Social economy, platform economy, collaborative economy, worker cooperatives, employment, self-employment, ilegal assignment of workers, Social Security. 


\section{SUMARIO $^{1}$}

I. Introducción. II. La prestación de servicios en un ecosistema digital: economía colaborativa vs. economía de plataformas. III. La organización del trabajo a través de las plataformas digitales. IV. El cooperativismo de plataformas y el rol de la cooperativa de trabajo asociado. V. Conclusiones. Bibliografía.

\section{Introducción}

La relevancia adquirida por las plataformas digitales constituye un fenómeno polimorfo de etiología diversa. Encuentra su origen en la automatización de las tareas de índole intelectual característica de la Cuarta Revolución Industrial. La creación de ingenios capaces de adoptar decisiones previamente programadas remedando el intelecto humano ha transformado lo que ya era un punto de encuentro conocido y frecuentado por buena parte de la sociedad, haciendo de él un entorno dominado por la organización de las relaciones en él entabladas.

La emergencia de esta organización virtual de las relaciones diferencia a la plataforma digital de aquellos ámbitos donde el usuario se limita a trabar conocimiento con otros individuos, como las redes sociales. También de aquellos otros que se conforman con permitir y propiciar la contratación por medios electrónicos. La informalidad que ha presidido dicha contratación fue superada merced a la promulgación de la Ley 34/2002, de 11 de julio, de servicios de la sociedad de la información y de comercio electrónico ${ }^{2}$, deudora de la Directiva 2000/31/CE del Parlamento Europeo y del Consejo, de 8 de junio de 2000, relativa a determinados aspectos jurídicos de los servicios de la sociedad de la información, en particular el comercio electrónico en el mercado interior (Directiva sobre el comercio electrónico) ${ }^{3}$.

1. Este trabajo es fruto del Proyecto de investigación titulado "Impacto de la digitalización y la Inteligencia artificial en la empresa y la sociedad: perspectivas jurídicas y económicas - E.S. Digital”. Referencia: PGC2018-093772-B-I00 (2019-2021), Ministerio de Ciencia, Innovación y Universidades, AEI/FEDER, UE, desarrollado dentro del Grupo GI-1876 "Empresa e Administración”, Grupo de Referencia Competitiva (ED431C 2019/15) del Programa de consolidación e estructuración de unidades de investigación competitivas nas universidades do Sistema Universitario de Galicia. Se enmarca, asimismo, dentro de la actividad investigadora desarrollada por el Centro de Estudios Cooperativos de la Universidad de Santiago de Compostela (CECOOP).

2. BOE no 166, de 12 de julio de 2002.

3. DOCE no 178 , de 17 de julio de 2000. 
Como antaño sucedió con la celebración de contratos por aquellos lares, también hoy la informalidad distingue el intercambio de prestaciones en las plataformas digitales, las cuales han sido ubicadas dentro de la economía colaborativa, sugiriendo el carácter extrajurídico de las relaciones en ellas concertadas. El desarrollo de un ordenamiento jurídico que, a menudo, adolece de cierta hipertrofia normativa aconseja replantear la naturaleza de unas relaciones cuya causa es, a menudo económica.

La evolución tecnológica deviene así presupuesto indispensable para el alumbramiento de unas plataformas cuyo auge hunde sus raíces en la depresión económica del año 2008. En un contexto marcado por la destrucción de empleo y la devaluación de las condiciones de trabajo, el ciudadano del s. XXI retomó prácticas que la sociedad de consumo parecía haber dejado atrás, consistentes en la compartición de activos como la vivienda, el medio de transporte, etc. Este modelo, basado en el intercambio, recibió la denominación de "economía colaborativa", en la medida en la que perseguía atender a necesidades específicas sin que sus participantes intervinieran en ella a título profesional. La diversa naturaleza de las necesidades cubiertas permitió su expansión en ámbitos tan dispares como el consumo, las finanzas o el conocimiento.

La eficacia de la que han hecho gala las plataformas digitales para canalizar esta suerte de "intercambio de favores", a menudo acorde con los postulados de la economía circular, pronto reveló su utilidad para vehicular servicios. Éstos podían ser ofrecidos por quienes, privados total o parcialmente de empleo, optaron por ofrecerlos por mero altruismo o para obtener la satisfacción de otra necesidad a cambio. No obstante, la destrucción de empleo reinante erigió estas plataformas en una vía de escape del desempleo, cuando aquellos servicios comenzaron a prestarse a título profesional. Es en este escenario donde se asiste a "una ofensiva a gran escala, global, en favor de "constructores de puentes digitales" que se insertan entre "quienes ofrecen servicios y quienes están en busca de estos"

Pero, en la medida en que el trabajo "no es una mercancía", como sostiene la Declaración relativa a los fines y objetivos de la Organización Internacional del Trabajo -en adelante, OIT-, de 10 de mayo de 1944 (Declaración de Filadelfia), aquél ha sido objeto de una especial atención por parte del derecho. Con arreglo a este principio, reiterado en la Declaración de la OIT sobre la justicia social para una globalización equitativa, adoptada por la Conferencia Internacional del Trabajo en su nonagésima séptima reunión de 10 de junio de 2008 , la prestación personal de servicios será acreedora de una especial protección que la sustrae del libre acuerdo entre las partes.

4. Vid. SCHOLZ, T.: Cooperativismo de plataforma. Desafiando la economía colaborativa corporativa, Dimmons, Barcelona, 2016, p. 9. 
Depararla exige, por consiguiente, encuadrarla en el ámbito de aplicación de alguna de las ramas del ordenamiento jurídico que de ella se ocupa. Entre aquéllas, ocupa un lugar preeminente el Derecho del Trabajo, de cuya huida se ha culpado en buena medida a la contratación a través de las plataformas digitales. Pero no sólo el del Trabajo se ha visto afectado por su aparición. También el Derecho de cooperativas encuentra en la plataforma un arma de doble filo que puede, ora constituir un catalizador del cooperativismo, ora encubrir un uso espurio de la cooperativa.

Procede, en consecuencia, trazar los difusos confines de la denominada economía colaborativa y diferenciarla de la economía de plataformas, susceptible de canalizar servicios de cuya regulación no pueden sustraerse los contratantes, so pretexto de la singularidad que el medio digital les imprime. Una vez identificados sus límites, interesa determinar a qué rama del ordenamiento jurídico concierne su tratamiento para, finalmente, comprobar la compatibilidad de este entorno digital con los principios cooperativos. Se trata, en definitiva, de averiguar qué rol está llamada a desempeñar la cooperativa y, en concreto, la de trabajo asociado, en este nuevo medio.

\section{La prestación de servicios en un ecosistema digital: economía colaborativa $v s$. economía de plataformas}

El calificativo que acompaña a la economía en la que se ha incardinado el trabajo desarrollado a través de plataformas digitales sugiere la participación en ella de agentes impulsados por el afán de colaborar de modo ocasional, mediante el ofrecimiento de productos o servicios susceptibles de satisfacer una necesidad ajena. Colaborar puede consistir, así, en ofrecer un bien o un servicio sin que medie contraprestación alguna. Cuando nada se aguarda a cambio, salvo la satisfacción de ayudar al prójimo, se está ante servicios amistosos, benévolos o de buena vecindad. El art. 1.3. d) del Real Decreto Legislativo 2/2015, de 23 de octubre, por el que se aprueba el texto refundido de la Ley del Estatuto de los Trabajadores -en adelante, ET- excluye de su ámbito de aplicación los trabajos realizados por "afecto personal, puro y desinteresado" , profesado a una persona física concreta. La existencia de un vínculo afectivo aleja "toda idea de pagar estos servicios o de alguna forma corresponderlos", pues "sólo, quizá, en la última fase de una amistad, lejana y perdida ésta se pierde al tiempo la voluntariedad de la interacción a la que la amistad está íntimamente ligada” ${ }^{6}$.

5. Vid. ALONSO OLEA, M.: "Trabajos familiares y amistosos, benévolos y de buena vecindad [art. 1.3.d) y e)]", Civitas. Revista española de derecho del trabajo, n. ${ }^{\circ} 100(1), 2000$, p. 84.

6. Idem. 
La "confianza entre desconocidos" que parece suscitar el entorno digital en modo alguno puede asimilarse al afecto que impulsa esta prestación, de modo que los servicios ofrecidos sin esperar contraprestación alguna podrán reputarse benévolos o de buena vecindad. Dejando a un lado aquellos supuestos donde la prestación de servicios persiga satisfacer un propósito moral, ideológico, o incluso religioso, destinándolos a un "ente colectivo", cabría considerar a los demás como una suerte de trabajos de "buena vecindad virtual" . Mientras que la vecindad tradicional estaba compuesta por "círculos reducidos de personas", siendo más propia de "los núcleos de población rústicos o urbanos mínimos de épocas pasadas" 10 , la "licuefacción de los códigos espacio temporales" 11 obrada por las nuevas tecnologías de la información y de la comunicación permite entablar relaciones salvando toda distancia geográfica.

Sin embargo, la confianza inspirada por este entorno digital no ha bastado para afianzar la buena vecindad como causa única que justifique la prestación de servicios a través de las plataformas. Sin menospreciar su incidencia en este fenómeno, acierta quien culpa a "la crisis del capitalismo global de 2008"12 con el consecuente "ciclo de aumento del desempleo y la precariedad laboral"13 del "auge de la economía colaborativa" ${ }^{14}$. No en vano buena parte de las iniciativas desarrolladas a través de plataformas digitales consisten en compartir un bien infrautilizado o en ofrecer un servicio que no se podía ejercer en el mercado a título profesional. El elevado número de desempleados que la depresión económica del año 2008 arrojó incrementó la

7. Vid. CARPIO GÁlVEZ, I. \& MONTES RUIZ, C.: "Economía colaborativa", RA \& DEM: Revista de Administración y Dirección de empresas, nº. 4, 2020, p. 55.

8. Vid. ALONSO OLEA, M., op. cit., p. 84.

9. Vid. VILLALBA SÁNCHEZ, A.: "Economía colaborativa, trabajo y cooperativismo de plataformas: la incidencia del punto de encuentro en la calificación del vínculo jurídico del prestador de servicios". En: Digitalización, inteligencia artificial y economía circular (dirs. GARCÍA NOVOA, C., VIVEL BÚA, M. \& coords. TORRES CARLOS, M. \& LADO SESTAYO, R.), Thomson Reuters-Aranzadi, Cizur Menor, 2021, en prensa.

10. Vid. ALONSO OLEA, A., op. cit., pág. 88.

11. Vid. ALEMÁN PÁEZ, F.: "El derecho a la desconexión digital (I). Una aproximación conceptual, crítica y contextualizadora al hilo de la "Loi Travail n. ${ }^{\circ} 2016-1088$ ", consultado en la base de datos de La Ley, documento 52/2017, p. 12.

12. Vid. RIVERA, J. DE, GORDO LÓPEZ, A.J. \& CASSIDY, P.R.: "La economía colaborativa en la era del capitalismo digital", Redes.com: revista de estudios para el desarrollo social de la Comunicación, nº. 15, 2017, p. 22. DOI: https://doi.org/10.15213/redes.n15. p22.

13. Idem.

14. Idem. 
oferta de estos servicios ocasionales, habida cuenta del tiempo disponible por parte de quienes habían sido privados, total o parcialmente, de un puesto de trabajo. El descenso del consumo que, a su vez, produjo la reducción de rentas del trabajo también compelió a buena parte de la población a compartir bienes que antańo hubieran sido comercializados, pero sobre los que luego apenas se solicitaba su uso temporal ${ }^{15}$. Fue así como la falta de demanda hizo resurgir el uso compartido de viviendas o de vehículos que otrora hubieran sido objeto de compraventa o de alquiler.

Resurgió, así, una economía informal, propia de tiempos anteriores a los que vieron florecer una sociedad del consumo basada en la adquisición y posterior desecho de productos. En ese sentido, no ha faltado quien haya alabado las virtudes de unas prácticas acordes con los principios de la economía circular, idóneas para permitir un aprovechamiento pleno de los productos a lo largo de toda su vida útil, e incluso tras la misma, desafiando el destino al que parece abocarlos la obsolescencia programada. Pero fue la plataforma digital que les dio soporte quien confirió un renovado protagonismo a unas prácticas lamentablemente destinadas a ocupar un espacio marginal en la economía. Ciertamente, antes de que las plataformas digitales hicieran su aparición, existía la costumbre de prestarse ayuda mutua para labores agrícolas en ciertas comunidades rurales. Aunque el Tribunal Supremo -en adelante, TS- negara base contractual alguna a esta práctica, la doctrina iuslaboralista identificó en ella la celebración de un "contrato civil innominado"16 considerando que, si bien el mismo era oneroso, resultaba ajeno al Derecho del Trabajo ${ }^{17}$.

La necesidad de obtener una contraprestación con la que subvenir a las necesidades del individuo y de su familia, fueran cuales fueran, justificó, largo tiempo ha, la contratación del trabajo a cambio de una contraprestación abonada en dinero. La imposibilidad de sobrevivir del trueque obligó así a contratar el trabajo, bien fuera por cuenta propia, bien fuera por cuenta ajena, siendo pronto advertida la debilidad de quienes lo ofrecían junto con un numeroso contingente de demandantes de empleo, carentes todos ellos de poder de negociación. La posibilidad de imponer unas condiciones de trabajo leoninas a un solicitante de empleo que, de negarse a aceptar-

15. Vid. GÓMEZ-ÁLVAREZ DÍAZ, R. \& MORALES SÁNCHEZ, R.: "Principios ontológicos de la economía colaborativa verdadera”. En: Economía Colaborativa... ¿De Verdad? (dirs. GÓMEZ-ÁLVAREZ, R., PATIÑO RODRÍGUEZ, D. \& coord. PLAZA ANGULO J.J.), Laborum, Madrid, 2018, p. 20. HANDLE: https://hdl.handle.net/11441/83089

16. Vid. ALONSO OLEA, A., op. cit., p. 87; con cita de la STS de 4 de diciembre de 1957.

17. Vid. BAYÓN CHACÓN, G.: "El intercambio de servicios", Revista Española de Derecho del Trabajo, no 21, 1957, p. 36. 
las, podría ser fácilmente sustituido por otro, pronto dio pábulo a una contratación abusiva que el Derecho del Trabajo nació para evitar.

Pues bien, la debilidad de la que estaba aquejado el trabajador durante la Primera Revolución Industrial afecta también al actual que, ante la imposibilidad de obtener un empleo en los mercados tradicionales, ha acudido a unas plataformas donde la misma práctica reaparece con inusitada crudeza ${ }^{18}$. El desempleo provocado por la depresión económica y agudizado por las medidas de austeridad adoptadas a posteriori empujaron así a quienes lo padecieron a unas plataformas caracterizadas por la despersonalización, la intercambiabilidad de sus usuarios y la organización automatizada de las prestaciones por ellas canalizadas ${ }^{19}$. Se asiste a un reclutamiento despersonalizado de prestadores, puesto que el acceso a la plataforma rara vez exige la acreditación de cualificaciones o destrezas específicas. Basta a menudo con que el interesado proporcione unos datos personales elementales para que inmediatamente le sean asignadas tareas cuya ejecución, al menos en apariencia, puede o no aceptar. La ausencia de una autenticación ${ }^{20}$, posible, incluso a distancia, mediante el tratamiento de datos biométricos, se entiende sólo en atención a la escasa especialización requerida para el desempeño de las tareas objeto de encargo.

Ésta justifica la intercambiabilidad de unos usuarios cuyas aptitudes pueden ser fácilmente reemplazadas por las de cualesquiera otros dispuestos a ofrecer sus servicios a través de la plataforma. Si bien este rasgo, que confiere escaso valor al servicio ofrecido, puede ser inherente a la tarea realizada, también se consigue troceando tareas complejas en micro tareas posteriormente distribuidas entre los diversos usuarios

18. A tal efecto, resulta particularmente esclarecedor el f. j. $18 .^{\circ}$ de la STS de 25 de septiembre de 2020 (rec. no 4746/2019), por la que se deduce el carácter laboral de la prestación de servicios ejecutada por repartidores contratada y organizada a través de una plataforma digital. Luego de describir el sistema a través del cual se articula el trabajo, aspecto que se retomará en siguiente epígrafe, reconoce que su funcionamiento se basa en el excedente de mano de obra del que la empresa disfruta "porque las microtareas se reparten entre una pluralidad de repartidores que cobran en función de los servicios realizados, lo que garantiza que haya repartidores que acepten ese horario o servicio que deja el repartidor que no quiera trabajar".

19. Vid. VILLALBA SÁNCHEZ, A.: "Los mecanismos de control del contrato de trabajo ante los procesos de contratación automatizada”. En: Congreso Interuniversitario OIT sobre el futuro del trabajo (comps. CARRERAS GARCÍA, J. HABOBA, S. \& LOBATO, J.), Vol. II, Ministerio de Trabajo y Economía Social, Madrid, 2021, pp. 439 y ss.

20. A tenor de la nota técnica "14 equívocos con relación a la identificación y autenticación biométrica", publicada por la AEPD en junio de 2020, la identificación consiste en el "proceso de reconocer a un individuo particular entre un grupo", mientras que la autenticación es el "proceso de probar que es cierta la identidad reclamada por un individuo" [documento disponible en el siguiente enlace: https://www.aepd.es/sites/default/ files/2020-06/nota-equivocos-biometria.pdf (consultado el día 5 de octubre de 2020]. 
de la plataforma ${ }^{21}$. Mediante este proceso han devenido contingentes trabajadores que, de asumir un encargo sustancial, gozarían de una singularidad que les otorgaría cierto poder de negociación.

Dicha distribución de tareas fue posible gracias a la última característica apuntada, cual es la organización automatizada de las prestaciones. Se avanzaba ab initio que la eclosión de la plataforma como ágora virtual dependió de los avances tecnológicos que han impulsado la Revolución Industrial en curso. Puesto que el rasgo que le otorga singularidad no es otro que la automatización de las tareas intelectuales, procede aludir a los sistemas basados en una inteligencia artificial capaces de adoptar decisiones de acuerdo con una lógica preestablecida por el ser humano.

Este atributo es el que da pie a la confusión entre la economía colaborativa y la economía de plataformas, que no tiene por qué albergar un mero intercambio de favores. A ella ha contribuido la ausencia de una definición legal y la vaguedad de las esbozadas en documentos como la Comunicación de la Comisión al Parlamento Europeo, al Consejo, al Comité Económico y Social Europeo y al Comité de las Regiones "Mejorar el mercado único: más oportunidades para los ciudadanos y las empresas", de 28 de octubre de $2015^{22}$. Para ésta, la economía colaborativa abarca "un complejo ecosistema de servicios a la carta y utilización temporal de activos basado en el intercambio a través de plataformas en línea”. También en la plataforma se centra el Dictamen del Comité de las Regiones Europeo -La dimensión local y regional de la economía colaborativa ${ }^{23}$, para el cual "la economía colaborativa hace un uso intensivo y amplio de las tecnologías digitales y la recogida de datos", constituyendo éstos "su materia prima". Elude, no obstante, concluir una descripción precisa, puesto que la "naturaleza innovadora y dinámica" del concepto impide definirlo "de forma terminante". Destaca, empero, que "sus agentes principales no actúan de la manera que suele suponerse en los modelos económicos clásicos [...] lo que no significa que no puedan ser racionales y centrarse en objetivos claros". Y, con ello, identifica lo que la distingue, al margen del medio a través del cual se despliega: la ausencia de profesionalidad que caracteriza la prestación ofrecida.

Bien es cierto que la Comunicación de la Comisión al Parlamento Europeo, al Consejo, al Comité Económico y Social Europeo y al Comité de las Regiones titu-

21. Vid. ALOISI, A.: "Commoditized workers: Case study research on labour law issues arising from a set of 'on-demand/gig economy' platforms”, Comparative Labor Law \& Policy Journal, no 3, 2016, p. 664. DOI: https://dx.doi.org/10.2139/ssrn.2637485

22. $\operatorname{COM}(2015) 550$ final.

23. DOUE C 51/28 de 10 de febrero de 2016. 
lada "Una Agenda Europea para la economía colaborativa”, de 2 de junio de 2016²4, siembra dudas al respecto al perseverar en la existencia de una plataforma a través de la cual se crea "un mercado abierto para el uso temporal de mercancías o servicios ofrecidos a menudo por particulares". A contrario sensu, considera también economía colaborativa la que implica a otros agentes distintos a los "particulares que ofrecen servicios de manera ocasional («pares»)". En ella se incluyen, de manera expresa, las operaciones realizadas por quienes "actúen a título profesional" con un evidente "ánimo de lucro".

Se admite sin tapujos que esta economía ha dejado de amparar la mera colaboración para crear "nuevas oportunidades [...] cuando las formas más tradicionales de empleo no son adecuadas [...] o no están a su disposición” ${ }^{25}$. Su virtualidad para cavar nuevos nichos de empleo en un contexto marcado por su desaparición y la destrucción del tejido empresarial justifica que la plataforma haya pasado de permitir el intercambio de servicios entre pares a posibilitar el acceso a un empleo que, a menudo, también se desempeña en ese entorno virtual.

La prestación de trabajo en un ámbito en principio dedicado al intercambio de servicios no profesionales propició, a tenor de la citada Comunicación, "cierta incertidumbre en cuanto a los derechos aplicables y el nivel de protección social”. O, en otras palabras, una huida del Derecho del Trabajo hacia una contratación libre de toda cortapisa. Confiesa, así, una visión menos optimista que la declarada por el citado Dictamen, según el cual esta economía "aumenta [...] el empleo y beneficia a los empleados, al permitir horarios más flexibles, que van desde microempleos no profesionales hasta el emprendimiento a tiempo parcial".

En suma, ni la economía colaborativa se desarrolla únicamente a través de las plataformas digitales, ni la economía de plataformas alberga únicamente prácticas propias de la economía colaborativa, sino cualesquiera formas de prestación de servicios conocidas en el mercado y reguladas por el legislador. Y, a menudo, canaliza la actividad de "empresas que generan pingües beneficios que sólo comparten con sus accionistas" ${ }^{26}$. En consecuencia, se considera más apropiado aludir a la "economía de plataformas" 27 como ámbito donde encuentran cabida las diversas formas de prestar servicios que se desgranarán acto seguido.

24. $\operatorname{COM}(2016) 356$ final.

25. Idem.

26. Vid. RODRÍGUEZ FERNÁNDEZ, M.L.: "Plataformas, microworkers y otros retos del trabajo en la era digital”, Futuro del Trabajo: Trabajo decente para todos, mes 3 (marzo), 2017, p. 6.

27. Vid. TODOLÍ SIGNES, A.: "Los retos del Derecho del trabajo ante la irrupción de la Economía de plataformas digitales”, El Cronista del Estado Social y Democrático de Derecho, n. o 75, 2018, p. 44. 


\section{La organización del trabajo a través de las plataformas digitales}

Tradicionalmente, la evolución tecnológica ha servido como dinamo transformadora de la organización del trabajo. Ella ha propiciado una división de tareas a raíz de la cual el individuo pasó a engarzarse como un eslabón más de una cadena productiva compuesta también por ingenios susceptibles de desempeñar funciones humanas. La primigenia automatización, acaecida durante la Primera Revolución Industrial, conllevó así una necesaria reorganización del trabajo en pos de una finalidad productiva. Huelga ańadir que dicha organización corría a cargo de quien ostentaba la titularidad de los medios de producción, encargado, a la postre, de diseñar o encomendar el diseño del engranaje necesario para su aprovechamiento.

Desde entonces, emergen dos paradigmas contrapuestos de prestación de servicios: el trabajo ejecutado por cuenta propia frente al trabajo realizado por cuenta ajena. Ambos comparten un rasgo, cual es su retribución. Su concurrencia los distingue de los trabajos benévolos, amistosos o de buena vecindad, excluidos del Derecho del Trabajo en virtud de lo dispuesto en e art. 1.3.d) ET y del de la Ley 20/2007, de 11 de julio, del Estatuto del trabajo autónomo ${ }^{28}$-en adelante, LETA-, cuyo art. 1.1 ciñe su ámbito de aplicación a quienes desempeñen "una actividad económica o profesional a título lucrativo". También del mero intercambio puntual de servicios, cuya regulación la doctrina ha atribuido al Derecho común de obligaciones y contra$\operatorname{tos}^{29}$, habida cuenta de la falta de profesionalidad que atañe unos los prestadores que actúan a cambio de un "favor", en modo alguno asimilable a una retribución. En los dos concurre, asimismo, la voluntariedad de unos servicios a cuya prestación uno se obliga mediante la celebración de un contrato.

Frente a sus atributos comunes, la ajenidad y la organización del trabajo son las características que trazan la diferencia entre el trabajo por cuenta propia y el trabajo prestado por cuenta ajena. La ajenidad es definida por el Diccionario de la Real Academia Española como "cualidad de las relaciones laborales por cuenta ajena, en contraposición a trabajo autónomo" 30 . Atendiendo a los resultados, no existe ajenidad cuando es el propio trabajador quien "adquiere o se beneficia inmediatamente

28. BOE no 166 , de 12 de julio de 2007.

29. Vid. ALONSO OLEA, A., op. cit., p. 87; y BAYÓN CHACÓN, G., op. cit., p. 36.

30. Disponible a través del siguiente enlace: https://dle.rae.es/ajenidad?m=form (consultado el día 14 de marzo de 2021). 
de los resultados productivos" ${ }^{31}$, pudiendo disfrutarlos o ponerlos a disposición otras personas a través de cualesquiera mecanismos jurídicos disponibles. El trabajo en cuestión puede "ser obra de un individuo aislado" ${ }^{2}$, pero resulta frecuente que "en sociedades industriales o postindustriales" ${ }^{33}$ aquél sea ejecutado "por un grupo de personas que adquiere conjuntamente los frutos o productos obtenidos o elaborados por el esfuerzo colectivo" 34 . En tales casos, la pertenencia al grupo puede venir dada por la preexistencia de un vínculo familiar, supuesto en el cual el art. 1.3.d) ET presume la exclusión de su ámbito de aplicación si aquél no supera el segundo grado o es de índole conyugal; o por la constitución de otro societario. En el primer caso, será de aplicación la LETA, en virtud de lo dispuesto en su art. 1.1. En el segundo, las relaciones serán disciplinadas por el Derecho societario. Si, por el contrario, los frutos o resultados del trabajo "no son adquiridos ni siquiera en un primer momento por el trabajador, sino que pasan directamente a otra persona, que se beneficia de ellos desde el instante en que se producen", existirá trabajo por cuenta ajena, sometido al ET.

A esta concepción clásica de la ajenidad, que atiende a los frutos del trabajo, deben aunarse otras particularmente esclarecedoras cuando de determinar la naturaleza de una prestación de servicios se trata. En la actualidad, ha cobrado singular relevancia la ajenidad concerniente a los medios o instrumentos de trabajo. Según esta manifestación, será trabajo ejecutado por cuenta ajena aquél en el cual los instrumentos de trabajo pertenezcan al empresario, siendo por cuenta propia aquel otro en el que se emplee un instrumental propio de trabajador.

El carácter societario que la Ley 27/1999, de 16 de julio, de Cooperativas ${ }^{35}$-en adelante, LC- atribuye al vínculo que media entre el socio trabajador y la cooperativa inscribe el trabajo del aquél dentro del ejecutado por cuenta propia. Ello implica, no sólo su comercialización por parte de la cooperativa, sino la titularidad de ésta de los medios o instrumentos esenciales necesarios para desarrollar el trabajo. Cuando la actividad tiene lugar dentro de la economía de plataformas, son éstas las que adquieren protagonismo como instrumentos de trabajo por excelencia. A tenor de la construcción clásica, no existiría cooperativismo de plataformas si la cooperativa no ostentara la titularidad de este ingenio, bien sea en propiedad, o mediante otro título.

31. Vid. MARTÍN VALVERDE, A., RODRÍGUEZ-SAÑUDO GUTIÉRREZ, F. \& GARCÍA MURCIA, J.: Derecho del Trabajo, Editorial Tecnos, Madrid, 2020, p. 50.

32. Ibidem, p. 51.

33. Idem.

34. Idem.

35. BOE n. ${ }^{\circ} 170$, de 17 de julio de 1999. 
Dejando a un lado el anterior, procede hacer mención aparte al segundo presupuesto que permite distinguir bien el trabajo en el seno de las cooperativas del prestado por cuenta ajena. Se alude a su organización. En función del modelo escogido, cabría distinguir entre el trabajo subordinado y el trabajo autónomo. Propia del primero es la prestación de servicios realizada "dentro del ámbito de organización y dirección de otra persona, física o jurídica, denominada empleador o empresario" (art. $1 \mathrm{ET})$. La inmersión dentro de un círculo organizativo ajeno es lo que dota al trabajo asalariado de una subordinación que se puede manifestar de forma más o menos evidente. Pocas dudas ofrece cuando se constata la impartición de órdenes e instrucciones a un trabajador que, a su vez, es objeto de vigilancia por parte del empresario o de la persona en la cual aquél delegara dicho poder, pudiendo ser sancionado de haber sido sorprendido incurriendo en falta. Este paradigma, propio de trabajos manuales ejecutados de forma presencial, ha sido superado, primero, en aquellas prestaciones cuyo contenido y cualificación requiere una mayor autonomía. Allí surgieron formas de subordinación "más sutiles y relajadas, no afectando a la lex artis o reglas técnicas de ejecución del trabajo"36. De esta guisa, la subordinación puede aparecer, ora como "sometimiento a órdenes" ${ }^{37}$, ora como "adaptación o acomodación de la propia actividad laboral a los objetivos, condicionamientos y programas de la organización productiva en la que aquélla se inserta" ${ }^{38}$.

De esa sutileza da muestra el vínculo que atañe a quienes prestan servicios en la economía de plataformas. Ante una prestación aparentemente caracterizada por la autonomía que confiere a sus usuarios, libres de elegir los encargos a realizar, así como el momento y el lugar donde cumplirlos, la STS de 20 de septiembre de $2020^{39}$ descubre una serie de indicios de subordinación. Así, la libertad que ostenta el trabajador para aceptar los encargos transmitidos por la plataforma y decidir, acto seguido, el momento y la ruta a través de la cual ejecutarlos, aparece seriamente condicionada. Se observa, en primer lugar, que, aunque el trabajador es dueño de elegir los encargos, se le premia si se decanta por la aceptación de los propuestos en las franjas horarias que acumulan un mayor número de pedidos. En segundo lugar, que la obtención de una puntuación modesta no sólo reduce sus ingresos, sino que puede llegar a acarrear una serie de represalias, entre las cuales destaca una desconexión que bien podría asimilarse a un despido disciplinario. Existe, por tanto, una organización ba-

36. Vid. MARTÍN VALVERDE, A. et al., op. cit., p. 53.

37. Ibidem, p. 52.

38. Idem.

39. Cit. 
sada en la existencia de un contingente de trabajadores a los que el desempleo, total y parcial, obliga a estar disponibles para aceptar el encargo que otro rechace, siendo éste penalizado si es renuente a aceptar los que le sean propuestos.

La existencia de esta organización bastó a algunos pronunciamientos para deducir la naturaleza laboral de una prestación de servicios cuyo contenido comportaba, por sus propias características, una mayor autonomía en su cumplimiento. Aconteció, p. ej., cuando el trabajo era ejecutado por unos traductores ${ }^{40}$ atendiendo, entre otros factores, a las consecuencias aplicadas en caso de no aceptar un encargo ${ }^{41}$. No obstante, la vigilancia panóptica ${ }^{42}$ que las nuevas tecnologías permiten desplegar sobre el individuo ha provocado un notable fortalecimiento del poder empresarial. Esta subordinación se deja percibir en la geolocalización constante del un repartidor que, con arreglo a las pautas proporcionadas por la empresa, debe cumplir sus encargos en un plazo máximo, empleando con la clientela los modales que la propia empresa indica. De todo ello deduce el TS que la titular de la plataforma "estableció instrucciones dirigidas a los repartidores relativas a cómo realizar la prestación del servicio” 43 que, a su vez, eran contrastadas mediante un sistema de valoración del desempeño basado las opiniones de la clientela ${ }^{44}$. De constatarse la inobservancia de alguna de las pautas indicadas, se aplicaban consecuencias disciplinarias, derivadas de "trece causas justificadas de resolución del contrato por la empresa consistentes en incumplimientos contractuales del repartidor: por retraso continuado en la prestación del servicio; realización deficiente o defectuosa de los servicios; ofensas verbales o físicas a las personas que presten servicios para [la compañía], proveedores o cualquier tercero relacionado con [la titular de la plataforma]; transgresión de la buena fe contractual o [...] abuso de confianza en el desempeńo de las funciones encomendadas". Hace

40. STS de 16 de noviembre de 2017 (rec. n.o 2806/2015).

41. Vid. SÁNCHEZ-URÁN AZAÑA, Y.: "Traductores e intérpretes judiciales y jurados. Existencia de relación contractual asalariada en una empresa que utiliza aplicación informática. Comentario a la STS de 16 de noviembre de 2017", Revista de Trabajo y Seguridad Social, 2017. Recuperado el 20 de marzo de 2021, de: https://eprints.ucm.es/id/eprint/46608/.

42. Concebido por BENTHAM con fines penitenciarios, el Panóptico consistía en una torre rodeada de un anillo compuesto por celdas individuales, donde cada sujeto era consciente de ser observado por un vigía oculto en la estructura central. Aquel ingenio "polivalente en sus aplicaciones", servía "también para [...] vigilar a los obreros" [vid. FOUCAULT, M.: Vigilar y castigar: nacimiento de la prisión, Siglo XXI Editores, Madrid, 2018, p. 238].

43. STS de 25 de septiembre de 2020 (cit.), f. d. 19. .

44. Véase, a tal efecto, la STS de 29 de diciembre de 1999 (rec. n. ${ }^{\circ}$ 1093/1999), que percibe como indicio de laboralidad la recepción de quejas procedentes de la clientela por parte de la empresa. 
notar la sentencia la coincidencia de buena parte de ellas con las susceptibles de justificar el despido disciplinario ex art. 54 ET.

Ambas variantes de subordinación son comprendidas en el Real Decreto-ley 9/2021, de 11 de mayo, por el que se modifica el texto refundido de la Ley del Estatuto de los Trabajadores, aprobado por el Real Decreto Legislativo 2/2015, de 23 de octubre, para garantizar los derechos laborales de las personas dedicadas al reparto en el ámbito de plataformas digitales ${ }^{45}$. Por él se ha convenido presumir sometida al ET "la actividad de las personas que presten servicios retribuidos consistentes en el reparto o distribución de cualquier producto de consumo o mercancía, por parte de empleadoras que ejercen las facultades empresariales de organización, dirección y control de forma directa, indirecta o implícita, mediante la gestión algorítmica del servicio o de las condiciones de trabajo, a través de una plataforma digital". Si bien dicha norma "se ha apartado de una concepción amplia de regular los supuestos de falsos autónomos", ciñéndose al "sector del reparto, sin alcanzar a otro tipo de plataformas digitales, como las de cuidados que eran especialmente reivindicadas por los sindicatos" ${ }^{46}$, las características de la subordinación descritas son predicables de los vínculos entablados mediante otras plataformas.

Que éstas hayan sido obra del intelecto humano y no un fruto espontáneo de la naturaleza explica que su creador haya querido extraer algún beneficio de su invención. Por ello, no ha de sorprender que su aplicación empresarial haya superado con creces su vocación de albergar iniciativas sin ánimo de lucro o de mero intercambio ocasional. Tales iniciativas, consistentes en el desarrollo de un proyecto, no pueden sino desplegarse con arreglo a un plan preconcebido que, si requiere de la intervención de varios actores, conlleva necesariamente su organización.

De lo anterior se deduce la frecuente aparición de plataformas basadas en un modelo jerárquico, característico de las relaciones laborales, hoy aplicado mediante algoritmos capaces de traducir y ejecutar automáticamente las decisiones empresariales. Algoritmos a los que el Real Decreto-ley 9/2021, de 11 de mayo ${ }^{47}$ quiere dotar de transparencia. Para lograrlo, se reconocerá a los representantes de los trabajadores el derecho a ser informados acerca de "los parámetros, reglas e instrucciones en los que se basan los algoritmos o sistemas de inteligencia artificial que afectan a la toma de decisiones que pueden incidir en las condiciones de trabajo, el acceso y manteni-

45. BOE no 113 , de 12 de mayo de 2021.

46. Vid. BAYLOS GRAU, A.: "El acuerdo social sobre la 'Ley riders", Según Antonio Baylos... Información, discusión y propuestas sobre las relaciones de trabajo y la ciudadanía social, 13 marzo, 2021. Recuperado el 14 de marzo de 2021, de: https://baylos.blogspot.com/2021/03/el-acuerdo-social-sobre-la-ley-riders.html

47. Cit. 
miento del empleo, incluida la elaboración de perfiles". Con ello, se pretende sacar a la luz posibles sesgos discriminatorios de la decisión automatizada al tiempo que facilitar "la negociación del algoritmo como un elemento central en la organización del trabajo, la determinación salarial y el registro del tiempo de trabajo" ${ }^{38}$.

Menos usuales son aquellas plataformas cuyos usuarios desarrollan una actividad "fuera del ámbito de dirección y organización de otra persona". De esta forma el art. 1 LETA define la ausencia de subordinación característica del trabajo autónomo. Fue así como la promulgación de la LETA vino a colmar "una laguna, ya tradicional, de nuestro ordenamiento jurídico, en donde el trabajo autónomo, como pone de relieve su Preámbulo, se ubicaba en el marco de relaciones jurídicas propio del derecho privado" ${ }^{49}$. Aunque, en el caso del TRADE, se admita la recepción de "indicaciones técnicas por parte de su cliente, también esta figura debe "desarrollar su actividad con criterios organizativos propios" [art. 11.2.d) LETA].

Sin embargo, la existencia de criterios organizativos propios en función de los cuales se desarrolle la actividad no impide que ésta sea ejecutada por parte de un grupo de individuos que, en pie de igualdad, se hayan dotado de una organización en común, constituyendo una sociedad ${ }^{50}$. En ese caso, las relaciones entabladas entre cada uno de ellos serán disciplinadas por el Derecho societario [art.1.3. g) ET], con independencia de que cada socio, individualmente considerado, se halle encuadrado en el Régimen Especial de los Trabajadores Autónomos -RETA- o, con carácter excepcional, en el Régimen General de la Seguridad Social.

Su inclusión en uno o en otro régimen se hace depender de que ostenten el "control efectivo, directo o indirecto", de la sociedad, con arreglo a lo dispuesto en los arts. 136.2.b) y 305.2.b) del Real Decreto Legislativo 8/2015, de 30 de octubre, por el que se aprueba el texto refundido de la Ley General de la Seguridad Social ${ }^{51}$-en adelante, LGSS-. Estarán, en todo caso, incluidos en el RETA cuando su participación en la sociedad alcance la mitad del capital social, presumiéndose, salvo prueba en contrario, que poseen el control efectivo si: 1) al menos, la mitad del capital de la sociedad para la que presten sus servicios está distribuido entre socios con los que convivan y a quienes se encuentren unidos por vínculo conyugal o de parentesco por consanguinidad, afinidad o adopción, hasta el segundo grado; 2) su participación en el capital social es igual o superior a la tercera parte del mismo o 3) su participación

48. Vid. BAYLOS GRAU, A., op. cit., passim.

49. Vid. FERREIRO REGUEIRO, C.: "El régimen jurídico del trabajo autónomo económicamente dependiente”, Estudios de derecho judicial, no 146, 2007, p. 102.

50. Idem.

51. BOE no 261, de 31 de octubre de 2015. 
en el capital social sea igual o superior a la cuarta parte del mismo, si tienen atribuidas funciones de dirección y gerencia de la sociedad [art. 305.2.b) LGSS].

Estas normas rectoras del encuadramiento cambian cuando el ente es una cooperativa de trabajo asociado. Aunque la relación de los socios con ella sea de índole societaria, el art. 14 LGSS permite a las cooperativas optar en sus estatutos por asimilarlos a los trabajadores por cuenta ajena y, por ende, integrarlos en el Régimen General de la Seguridad Social, o por encuadrarlos en el Régimen Especial de los Trabajadores Autónomos. Que la cooperativa ofrezca esta posibilidad, inexistente en las sociedades capitalistas, le ha granjeado la atención de quienes desean hacer de ella un uso ajeno a los principios inspiradores del movimiento cooperativo. Interesa, por tanto, determinar si la economía social, en general, y el cooperativismo de trabajo asociado, en particular, encuentran un terreno fértil para desarrollarse dentro de la economía de plataformas.

\section{El cooperativismo de plataformas y el rol de la cooperativa de trabajo asociado}

La LC es contundente al atribuir naturaleza societaria a la relación entablada entre los socios y la cooperativa de trabajo asociado. Ésta tiene por objeto proporcionarles "puestos de trabajo, mediante su esfuerzo personal y directo, a tiempo parcial o completo, a través de la organización en común de la producción de bienes o servicios para terceros" (art. 80.1 LC). Y no un trabajo cualquiera, sino un empleo acorde con los postulados de la economía social.

Como corresponde a todas las entidades pertenecientes al Tercer Sector, en ellas priman las personas y el fin social sobre el capital. A su cuidado atenderá una gestión autónoma y transparente, democrática y participativa que lleva a priorizar la adopción de decisiones "en función de las personas y sus aportaciones de trabajo y servicios" [art. 4.a) LES]. Por consiguiente, sus resultados estarán predestinados a recompensar el trabajo aportado por sus miembros o a la consecución del fin para el cual han sido constituidas. [art. 4.b) LES].

La preeminencia de la persona y del fin social no debe dar pie a confundir a estas entidades con aquellas otras de índole benéfica, que también hallaban un espacio, quizá angosto, en el seno de la economía de plataformas. Éstas organizan una prestación de servicios ejecutada por mera benevolencia que, a lo sumo, puede comportar una compensación de los gastos generados por dicha actividad [art. 14.2.d) de la Ley 45/2015, de 14 de octubre, de Voluntariado ${ }^{52}$. Alejándose de este arquetipo, las 
entidades pertenecientes a la economía social desarrollan "actividades económicas y empresariales" en el ámbito privado, con independencia de que en su gestión se otorgue primacía a sus integrantes y/o al interés social sobre la mera obtención y reparto de beneficios. Se erigen, así, en verdaderos actores del mercado, dado que concurre en ellas el aliciente que líneas atrás se advertía como prácticamente imprescindible para el costoso desarrollo de una plataforma. Así, aunque el ánimo de lucro no constituya el catalizador de su actividad, sí concurre en ellas el propósito económico que mueve a casi todos los participantes en la economía de plataformas.

La diversidad de actividades que engloba el Tercer Sector explica que algunas de sus entidades se hayan zambullido en las procelosas aguas de la economía de plataformas. Se alude, en concreto, a las denominadas "cooperativas de plataformas" o "cooperativas digitales". La doctrina las ha definido como entes amparados por los principios y valores de la economía social que llevan a cabo su actividad económica conforme a la legalidad a través de la red; bien porque carecen de sede física donde realizarla, bien porque la actividad en cuestión requiere, para poder ser desarrollada con plenitud, de un punto de encuentro online ${ }^{53}$. Además de abaratar costes, su propósito estriba, a menudo, en alcanzar una clientela más dispersa y, con frecuencia, permitir que los socios trabajadores presten servicios en el lugar que resulte de su elección, favoreciendo así la cohesión territorial.

Se combina así una actuación conducente al éxito del modelo de negocio emprendido con el respeto de los postulados de la economía social, entre los cuales destaca, desde la perspectiva interna, la conciliación de la vida personal y familiar de sus integrantes. Y, desde un punto de vista externo, la solidaridad con la sociedad en general, para con la cual se adquiere el compromiso de contribuir al desarrollo local, a la igualdad de oportunidades entre hombres y mujeres, a la cohesión social, a la inserción de personas en riesgo de exclusión social y la generación de empleo estable y de calidad. [art. 4. c) y d) LES]. Cabría asimismo añadir, o incluir dentro del compromiso de estos entes, la actividad medioambientalmente responsable que desarrollan unas cooperativas que, mediante el uso intensivo del entorno digital, evitan desplazamientos innecesarios en el entorno físico, ahorrando el gasto de combustibles contaminantes.

La libre adhesión que confieren a sus miembros, la gestión democrática que las inspira y su vocación social parece distinguirlas como la forma jurídica más adecuada para canalizar iniciativas que, sin presentar un propósito meramente altruista, irro-

53. Vid. ARRIETA IDIAKEZ, F.J.: "Las cooperativas digitales como cauce para el trabajo digital en el contexto de la economía colaborativa", Revista de derecho social, n. ${ }^{\text {o }}$ 85, 2019. p. 238; y GUTIÉRREZ BENGOECHEA, M. \& SÁNCHEZ-ARCHIDONA HIDALGO, G.: Aspectos tributarios de las cooperativas y sociedades laborales, Editorial Comares, Granada, 2006, pp. 34 y ss. 
guen beneficios colectivos y sociales más allá del ánimo de lucro de sus integrantes. No en vano el Dictamen del Comité Económico y Social Europeo sobre «Consumo colaborativo o participativo: un modelo de sostenibilidad para el siglo $\mathrm{XXI}{ }^{54}$ erige al cooperativismo en el principal aliado de la economía colaborativa "en la medida en que [las cooperativas] conjugan y comparten principios y valores"; aunque en su posterior Dictamen sobre "La economía colaborativa y la autorregulación" 55 se desdiga, desterrando allende las fronteras de la economía colaborativa a mutualidades y cooperativas ${ }^{56}$. Lo anterior se comprende, en la medida en que se confunda economía colaborativa con economía de plataformas, dado que las cooperativas trascienden la mera colaboración entre particulares, constituyéndose con un propósito económico. Encuentran, no obstante, encaje dentro de la economía de plataformas, en tanto ecosistema tecnológico susceptible de albergar iniciativas con o sin ánimo de lucro, siendo las primeras las que lo han colonizado.

Pero no sólo la existencia de un propósito económico, susceptible de respaldar la viabilidad de las cooperativas digitales, justifica su admisión como una vía independiente para intervenir de un modo socialmente responsable en la economía de plataformas. Su actuación debe guiarse, además por determinados principios. De acuerdo con la Declaración sobre la identidad cooperativa, adoptada por la Asamblea General de la Alianza Cooperativa Internacional en 1995 y contenida en la Recomendación no 193 (2002) de la OIT sobre la promoción de las cooperativas, éstas se rigen, en primer lugar, por el principio de adhesión voluntaria y abierta. Éste las configura como "organizaciones voluntarias, abiertas a todas las personas capaces de utilizar sus servicios y dispuestas a aceptar las responsabilidades de ser socio, sin discriminación social, política, religiosa, racial o de sexo". Este rasgo encontraría encaje en unas plataformas cuya accesibilidad contribuyó a su éxito, permitiendo el acceso al empleo de individuos que no eran capaces de encontrarlo en un entorno físico azotado por la crisis económica y marcado por la soledad que padece el individuo del siglo en curso. El establecimiento de criterios de acceso, en tanto vengan justificados por la actividad que el socio deba desarrollar, tales como el ostentar cierta cualificación, no obstarían a lo afirmado.

El segundo de los principios enunciados por la citada Declaración no es otro que la gestión democrática por parte de sus socios. A tenor de aquél, éstos "participan activamente en la fijación de sus políticas y en la toma de decisiones". En consecuen- 
cia, "los hombres y mujeres elegidos para representar y gestionar las cooperativas son responsables ante los socios", teniendo los socios "iguales derechos de voto". Se distancian así del paradigma a través del cual se ha encubierto el trabajo subordinado, cuya sumisión debida al Derecho del Trabajo ha granjeado una infausta fama a la economía de plataformas. La cooperativa digital no puede consistir, por consiguiente, en un entorno donde aparentemente interactúen sujetos independientes que, en realidad, se hallen sometidos a un poder superior. La existencia de un proyecto personal, no común, gobernado por quien asume la dirección de la persona jurídica titular de la plataforma, disipa todo ideal de cooperación ${ }^{57}$. También se diferencia de la mera confluencia de trabajadores autónomos que ejercen su actividad de manera independiente compartiendo apenas un espacio virtual común, puesto que al paradigma cooperativo le es propia una organización. Sucede que la misma está orquestada por sus miembros, quienes son libres de consignar las decisiones adoptadas en un algoritmo capaz de ejecutarlas de forma automática, poniendo orden en la actividad que la cooperativa desarrolla.

La necesaria existencia de esta organización en común impide, asimismo, considerar que una verdadera cooperativa sea aquella cuyo cometido consista en la mera puesta a disposición de los socios a otras empresas. En tal caso, podría existir una cesión ilegal de trabajadores utilizando la cooperativa de trabajo asociado como un mero ente interpuesto (art. 43 ET). Dado que el art. 7 de la Recomendación nº 193 de la OIT (2002) sobre la promoción de las cooperativas, advierte a los signatarios acerca de la necesidad de "velar por que no se puedan crear o utilizar cooperativas para evadir la legislación del trabajo" y establecer así "relaciones de trabajo encubiertas", deviene preciso "luchar contra las seudo-cooperativas, que violan los derechos de los trabajadores.

Por fortuna, el TS parece haber dejado atrás su posición proclive a admitir la existencia de una organización propia cuando una cooperativa destinara a cumplir con el encargo de otra empresa a un número reducido de trabajadores, los cuales que recibían órdenes de sus propios Jefes de Equipo ${ }^{58}$. Órdenes que, por lo demás, no hacían sino transmitir las instrucciones recibidas de la empresa contratista en cuyos locales, arrendados por la cooperativa, los socios ejecutaban su actividad valiéndose de herra-

57. Las decisiones son, así, "tomadas por sus socios, quienes adoptan estructuras de organización horizontales y verticales, par ser más eficientes, con distribución de competencias entre los distintos órganos y cargos, cargos a los que todos pueden aspirar, así como crear comisiones que controlen o supervisen la gestión de los administradores" [vid. FAJARDO GARCÍA, I.G.: "Naturaleza jurídica de la realización entre la cooperativa de trabajo asociado y el socio-trabajador". En: Cooperativa de trabajo asociado y estatuto jurídico de sus socios trabajadores (dir. FAJARDO GARCÍA, I.G. \& coord. SENENT VIDAD, M.J.), Tirant lo Blanch, València, 2016, p. 23]. 
mientas proporcionadas por aquélla. Con la STS de 18 de mayo de $2018^{59}$, adquiere "especial relevancia la acreditación de la actividad que realmente desempeña la cooperativa para constatar que con ello se evidencia la efectiva creación y organización de mecanismos de actuación interna y de relación con los clientes [...] de los que se desprenda la prestación de servicios de cualquier tipo a sus asociados, generando y fomentando fórmulas de gestión empresarial, ya sea en el ámbito puramente material, de asesoramiento, de reducción de costes, de captación de clientes, o cualquier otro que incida en el mejor desarrollo de la prestación de servicios de sus asociados". Desde entonces, debe reputarse cesión ilegal el reclutamiento de socios trabajadores con el único propósito de ponerlos a disposición de otras empresas sin proveerlos de "estructuras organizativas, materiales, financieras, de gestión, o de cualquier otra clase, que permitan y faciliten la más eficaz prestación del trabajo autónomo a través de la puesta en común del esfuerzo personal y directo de [quienes] la integran"60.

Mediante la definición de lo que ha de considerarse como una cesión ilegal se describe, con cierta precisión, la actividad propia de una cooperativa de trabajo asociado, que tampoco puede encubrir su constitución como un mero ente interpuesto a través del cual los socios puedan desempeñar un trabajo autónomo individual, al margen de dicha organización común. Tal acontece con las aparentes "cooperativas online de trabajo asociado" ${ }^{1} \mathrm{o}$ "cooperativas de facturación", dedicadas a captar profesionales a quienes ofrecer un régimen fiscal y de encuadramiento en la Seguridad social a medida. Su principal aliciente estriba en la facultad que el art. 14 LGSS confiere a los estatutos de las cooperativas de trabajo asociado para asimilar a sus socios trabajadores a trabajadores por cuenta ajena, integrándolos en el Régimen General (siempre y cuando no queden, por razón de su actividad, incluidos en alguno de los regímenes especiales que incluyen trabajadores por cuenta ajena); o encuadrándolos en el RETA.

Su propósito no consiste en proporcionar puestos de trabajo a sus socios a fin de desarrollar un proyecto empresarial común y participativo, sino en prevalerse del encuadramiento ad hoc que ofrece la LGSS, razón por la cual algunas no han tardado en ser objeto de descalificación ${ }^{62}$. En éstas brilla también por su ausencia la participa-

59. Rec. n. ${ }^{\circ} 3513 / 2016$.

60. STS de 18 de mayo de 2018 (rec. n. ${ }^{\circ}$ 3513/2016).

61. Vid. LACOMBA PÉREZ, F.: “El dudoso fenómeno de las cooperativas 'online' de trabajo asociado o cooperativas de facturación”, Lex Social: Revista jurídica de derechos sociales, vol. 7(2), 2017, p. 272.

62. Véase el supuesto de la sociedad cooperativa Fidelis Factu, S. Coop: https://www.rtve.es/noticias/20170817/ empleo-descalifica-factoo-como-cooperativa-supone-su-disolucion/1599141.shtml (consultada el día 2 de diciembre de 2020). 
ción económica de los socios, así como la asignación de los beneficios a reservas o su reparto mediante la entrega de anticipos societarios. Su abono no se decide sino en función de lo recibido por la clientela procedente de cada socio, de cuyo importe se deducen ciertas cantidades en concepto de gastos de gestión. No deja de sorprender que este paradigma, caracterizado por el pago de parte de las ganancias de cada socio para el mantenimiento de la plataforma, sea asimilado al cooperativismo de plataformas por el Informe de la OIT Word employment and social outlook: The role of digital labour platforms in transforming the world of work ${ }^{63}$.

Procede, no obstante, distanciarse de este criterio para concluir que este fenómeno, auspiciado por la economía de plataformas, sólo está vinculado a la economía social en apariencia ${ }^{64}$, aunque no falte quien ensalce sus virtudes para aglutinar el poder de negociación de sus participantes frente a las grandes empresas que campan a sus anchas en ese ecosistema ${ }^{65}$. A decir verdad, quienes prestan servicios a través de plataformas virtuales permanecen "invisibles, aislados entre algoritmos" ${ }^{\text {". Acierta, }}$ por tanto, quien los compara con los trabajadores domésticos. Tanto los unos como los otros están aquejados de un distanciamiento que ha obstaculizado, de forma casi insalvable, la defensa de sus intereses colectivos. Con el afán de salvar esta distancia se

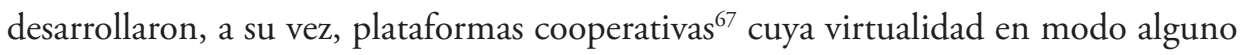
debe suplantar a la acción sindical.

Sobre este extremo, procede reparar en la superación de la tesis sostenida por la SAN de 17 de noviembre de $2017^{68}$, según la cual los socios trabajadores de las cooperativas de trabajo asociado no ostentarían el derecho a la libertad sindical, "cuyo despliegue en una relación societaria [la] distorsionaría y desequilibraría”. Se atiene a la literalidad del art. tercero de la Ley Orgánica 11/1985, de 2 de agosto, de Libertad

63. International Labour Office, Ginebra, 2021, p. 88.

64. Vid. ARRIETA IDIAKEZ, F.J., "Las cooperativas...”, pp. 238 y ss.

65. Vid. CHARLES, J., FERRERAS, I. \& LAMINE, A.: "A freelancers' cooperative as a case of democratic institutional experimentation for better work: a case study of SMart-Belgium", Transfer: European Review of Labour and research, vol. 26(2) p. 157. DOI: https://doi.org/10.1177/1024258920919686

66. Vid. SCHOLZ, T.: Cooperativismo..., p 19. Sobre el aislamiento de los trabajadores reclutados a través de plataformas digitales y su debilidad, pese a la elevada cualificación que algunos ostentan, hace también hincapié en GAGLIARDI, D. et al.: New Technologies and Digitisation: Opportunities and Challenges for the Social Economy and Social Enterprises. European Commission, Executive Agency for SME, 2020, p. 106. DOI: https://doi.org/10.2826/667682.

67. Cuya relevancia para canalizar la acción colectiva de quienes prestan servicios a través de las plataformas digitales fue puesta de relieve por el Informe de la OIT Word employment and social outlook: The role of digital labour platforms in transforming the world of work, cit., p. 24.

68. No $277 / 2017$. 
Sindical ${ }^{69}$, que sólo permite afiliarse a una organización sindical a "los trabajadores por cuenta propia que no tengan trabajadores a su servicio, omitiendo toda referencia al socio trabajador. No lo considera, por consiguiente, asimilable al trabajador autónomo, "puesto que su prestación de trabajo no se organiza personalmente por él", sino "en común por la sociedad cooperativa, con la que mantiene una relación societaria"70. Conociendo sobre el mismo asunto, la STS de 8 de mayo de $2019^{71}$ consideró que "la amplitud del derecho de libertad sindical [...] no admite restricciones en aquellos supuestos [...] en donde hay una prestación de trabajo subordinada, aunque las notas de dependencia y, especialmente, la de ajenidad, ofrezcan un perfil menos intenso que el de la relación laboral típica o común".

Fue así como, en atención al "carácter mixto" del "status jurídico del socio-trabajador", se consideró que no sólo "los socios trabajadores de una cooperativa de trabajo asociado tienen derecho a afiliarse libremente al sindicato de su elección”, sino que también "los sindicatos legalmente constituidos tienen derecho al libre ejercicio de la actividad sindical en las Cooperativas de Trabajo Asociado donde tengan afiliados socios trabajadores" (sic. ${ }^{72}$. Desde entonces, cualquier reivindicación que los socios puedan oponer a la organización común del trabajo debe canalizarse a través de la representación sindical, habida cuenta del vínculo de subordinación que la Sala estima existente, aunque el mismo provenga de decisiones democráticamente adoptadas.

La sustitución de la acción sindical por el asociacionismo orquestado a partir de la cooperativa puede, por el contrario, encubrir la mera interposición de un ente que en nada se parece a una cooperativa de trabajo asociado. En tales casos, la existencia de verdaderos trabajadores, con arreglo al art. 1.1 ET, justifica de por sí su defensa mediante el sindicato, pero no ante la aparente cooperativa, sino ante la empresa titular de la plataforma.

También ese "carácter mixto" del estatuto jurídico del socio trabajador atenúa, en cierto modo, la "propiedad" del trabajo, a la sazón prestado en el seno de una sociedad, por contraposición a la ajenidad que caracteriza al sometido al Derecho del Trabajo. Aunque no reciba mención expresa por parte del Derecho de cooperativas, ella obedece la expulsión de los socios trabajadores del ámbito del Derecho del Trabajo. Sí se deja entrever en la LETA, cuando erige en presupuesto indispensable

69. BOE no 189 , de 8 de agosto de 1985.

70. Vid. GARCÍA JIMÉNEZ, M.: "Falsas cooperativas, usos abusivos y derechos de los trabajadores. Análisis jurisprudencial y propuestas de actuación”, CIRIEC-España. Revista Jurídica de Economía Social y Cooperativa, no 33, 2018, p. 196.

71. Rec. no 42/2018.

72. Cit. 
para el reconocimiento de la condición de trabajador autónomo económicamente dependiente -en adelante, TRADE- el "disponer de infraestructura productiva y material propios, necesarios para el ejercicio de la actividad e independientes de los de su cliente, cuando en dicha actividad sean relevantes económicamente" [art. 11.2.c) LETA]. Puesto que el TRADE no es un "una especie de híbrido o tertius genus entre el trabajador por cuenta ajena y el trabajador por cuenta propia ${ }^{73}$, sino un trabajador por cuenta propia, cualquiera que se precie de serlo debe estar en condiciones de ostentar la titularidad de dicha infraestructura.

Acontece, no obstante, que el movimiento cooperativo parte de aunar esfuerzos para el desarrollo de actividades empresariales. Ello comporta la puesta en común del trabajo, pero también del capital necesario para disfrutar de instrumentos propios. La titularidad de éstos corresponderá, por consiguiente, a la cooperativa. Y, siendo la plataforma la herramienta imprescindible para que el cooperativismo se introduzca dentro de la economía de plataformas, corresponde a la sociedad cooperativa ostentar la titularidad de aquella. De la relevancia que la plataforma adquiere en este ecosistema dio testimonio la STS de 20 de septiembre de $2020^{74}$. En ella se calificó de esencial para el ejercicio de la actividad la infraestructura consistente en "el programa informático" o "plataforma" que "[ponía en contacto a los comercios con los clientes finales" 75 . Por contraposición, se reputaron "accesorios"76 la motocicleta y el teléfono móvil aportados por los quienes accedían a un empleo a través de plataformas dedicadas al reparto.

Con arreglo a lo anterior, constituye seña distintiva de las cooperativas de trabajo asociado de plataformas la titularidad de la misma por parte de sus socios ${ }^{77}$. Sin embargo, el elevado coste que implica su diseño, construcción y mantenimiento explica que acostumbren a ser desarrolladas por grandes empresas. No en vano han devenido protagonistas absolutas en ese ámbito, relegando a un segundo plano a otras iniciati-

73. Véase, en el mismo sentido, MOLERO MANGLANO, C.: "La configuración legal del autónomo dependiente: problemas y viabilidad (Un estudio del artículo 11 de la Ley 20/2007)", Actualidad Laboral, no 2, 2008; consultado a través de la base de datos de La Ley (documento no 6686/2007), p. 2. Ello es así, toda vez que el objeto y finalidad de [la LETA fue] regular un marco protector de derechos y obligaciones para aquellos trabajadores autónomos (por cuenta propia) que perciban de un cliente, al menos, el $75 \%$ de sus ingresos por rendimientos de trabajo y de actividades económicas o profesionales" [STSJ Castilla -La Mancha, de 24 de enero de 2018 (rec. no 1797/2016)].

74. Rec. no 4746/2019.

75. Idem.

76. STS de 20 de septiembre de 2020 (cit.).

77. Como evidencia el Informe de la OIT Word employment and social outlook: The role of digital labour platforms in transforming the world of work, International Labour Office, cit., p. 88. 
vas benévolas o basadas en la colaboración entre particulares. Puesto que la inversión de unos fondos de los que carecen buena parte de las empresas constituye la barrera que impide su acceso a ese mercado, parece razonable el desarrollo de políticas de fomento por parte de los poderes públicos. Éstas podrían abarcar, desde medidas de financiación, hasta otras de asesoramiento legal o tecnológico, pudiendo consistir en el desarrollo de espacios para su puesta a disposición de las empresas o incluso en la transferencia tecnológica desde las instituciones consagradas a la investigación.

Aunque este tipo de iniciativas podrían estar dirigidas a pequeñas empresas y emprendedores, el retorno positivo que las cooperativas de trabajo asociado aportan, no sólo a sus socios, sino a la comunidad en la cual se integran, justificaría destinarlas prioritariamente a estos entes pertenecientes a la economía social. De esta guisa, un fenómeno surgido al margen de los mercados tradicionales bajo la consigna de la colaboración, encontraría acomodo en un Tercer Sector donde el desarrollo de una actividad económica no está reñido con la búsqueda del interés colectivo de sus socios y del interés general, económico y social.

A la titularidad de la plataforma debe sumarse otros dos indicios actualmente asociados al desarrollo de una actividad empresarial propia. El primero, consiste en actuar en el mercado bajo la imagen de la cooperativa, y no de la empresa cliente. A tal efecto, la doctrina ha entendido que existiría "ajenidad en la marca"78 cuando el trabajador portara en el ejercicio de sus funciones los distintivos de la empresa cliente, sirviendo de heraldo de una marca ajena. Cuidar los signos externos adquiere especial relevancia en los supuestos de contratación y subcontratación de obras y servicios. El segundo, estriba en dominar la materia prima esencial a partir de la cual se desarrollan los negocios propios de la economía de plataformas: los datos. De esta guisa, existirá "ajenidad en los datos"79, cuando la empresa cliente monopolice la información relativa a los socios trabajadores y a la clientela, acaparando toda "la [...] necesaria para el manejo del sistema de negocio" ${ }^{" 0}$. Por el contrario, será cooperativizada aquella actividad cuyos datos sean gestionados de manera democrática por parte de los socios. El tratamiento de esta información, fruto de decisiones democráticamente adoptadas, podrá, por consiguiente, dotar de cierta transparencia a la gestión algorítimica de la organización.

78. Vid. TODOLÍ SIGNES, A.: "El impacto de la 'Uber economy' en las relaciones laborales: los efectos de las plataformas virtuales en el contrato de trabajo", IUS Labor, no 3, 2015, p. 6.

79. Vid. VILLALBA SÁNCHEZ, A.: "Economía...”, p. 14.

80. STS de 20 de septiembre de 2020 (cit.). 
Siendo los anteriores los rasgos que permiten la identificación de una cooperativa de trabajo asociado ${ }^{81}$, procede ańadir que aquéllas cuya actividad se despliega en un entorno digital bien pueden contribuir a la educación, información y formación de sus miembros. Siendo éste otro de los principios rectores del cooperativismo, huelga aludir a la probada eficacia de las nuevas tecnologías para canalizar acciones formativas de carácter síncrono o asíncrono en todos los niveles educativos. Pero, a ella, procede añadir la posibilidad de acreditar dicha formación mediante el empleo de la tecnología de registro distribuido -en adelante, DLT-, en general, y de la basada en la cadena de bloques -o blockchain- en particular. Ésta no sólo permite la llevanza colaborativa de registros donde quede constancia de la superación de una acción formativa, sino que permite también su acreditación por cotejo mediante la aplicación de un algoritmo al texto íntegro del documento original, a fin de constatar su coincidencia con el aportado si arroja el mismo código ${ }^{82}$.

Su potencial para contribuir a la formación continua de sus socios, tanto en disciplinas conexas a su propia actividad, como en cuanto concierne a la adquisición de competencias digitales, contribuyendo así a la superación de la brecha digital, justifica su impulso desde los poderes públicos. Dicha promoción, en modo alguno contraria al principio de autonomía e independencia de las cooperativas, comprende, la colaboración público-privada ${ }^{83}$. Aunque no quepa asimilar la prosecución del interés general que inspira la actuación de los poderes públicos con su defensa del interés común, sí es dable extraer puntos de convergencia que justifiquen su acción conjunta. Dado que la creación de empleo digno constituye un propósito cuya consecución debe orientar tanto a los poderes públicos, como a las cooperativas de trabajo asociado, procede abogar por dicha colaboración. Así, a la labor de control de la legalidad desplegada por la Inspección de Trabajo a fin de erradicar el uso de las falsas cooperativas, podría ańadirse un esfuerzo por promover el desarrollo del cooperativismo dentro de la economía de plataformas.

Además de las medidas de fomento económico, destinadas a salvar el obstáculo económico que a menudo impide acometer el desarrollo de la plataforma digital,

81. Vid. TODOLÍ SIGNES, A.: "La jurisprudencia del Tribunal Supremo en materia de falsas cooperativas". En: La promoción del emprendimiento y la inserción social desde la economía social (coord. FAJARDO GARCÍA, I.G.), CIRIEC-España, València, 2018, p. 87.

82. Vid. MARTÍNEZ CASTAÑO, R.: "Blockchain: introducción técnica". En: 4. ${ }^{a}$ Revolución industrial: impacto de la automatización y la inteligencia artificial en la sociedad y la economía digital (dirs. GARCÍA NOVOA, C. \& SANTIAGO IGLESIAS, D.), Thomson Reuters-Aranzadi, Cizur Menor, 2018, p. 298.

83. Vid. ARRIETA IDIAKEZ, F.J.: "La colaboración público-privada en el fomento de la economía colaborativa en el ámbito local: Una alternativa a la economía informal que trae causa de la falsa economía colaborativa", Lan Harremanak, no 41, 2019, p. 84. DOI: https://doi.org/10.1387/lan-harremanak.20877 
destaca, por último, el papel que las instituciones educativas, en general, y la universidad, en particular, están llamadas a desempeñar para promocionar el aprovechamiento cooperativo del entorno digital. No ha faltado quien destacó la importancia de los estudios cooperativos a la hora de preparar egresados capaces de desarrollar un proyecto exitoso ${ }^{84}$. Tampoco quienes hayan subrayado el crucial papel de las instituciones educativas, en colaboración con los gobiernos, de cara a la "fertilización cruzada entre el emprendimiento social y el mundo digital peer-to-peer a través de múltiples acciones, como "incubadoras específicas, herramientas y políticas de financiación, y proyectos de colaboración" ${ }^{75}$.

Líneas atrás se reconocía que, si bien la aparición de la economía de plataformas fue posible gracias al desarrollo tecnológico, su auge dependió, en buena medida, de una escasez de empleo que sufrió especialmente la juventud. De nuevo ante un contexto económico difícil, marcado por la pandemia en curso, procede recordar la importancia de la formación para el desarrollo de iniciativas que, en el marco de la economía social, permitan a los jóvenes dotarse de un proyecto común que les proporcione un empleo digno cuando éste constituya un bien escaso.

\section{Conclusiones}

El desarrollo de plataformas digitales permitió tender puentes entre oferentes y demandantes de servicios, difuminado toda frontera y conjurando su aislamiento. Surgidas como un ecosistema novedoso, albergaron, al margen de toda regulación, relaciones de mera colaboración entre particulares cuyo auge estaba inescindiblemente vinculado a la depresión económica de principios de siglo. Pero, en la medida en que su creación supone una notable inversión, el esfuerzo empeñado en su concepción a menudo tuvo como móvil un propósito económico. Proliferaron, así verdaderos modelos de negocio que impiden asimilar la economía colaborativa a la economía de plataformas, formando aquélla sólo una pequeña parte de ésta.

La informalidad que presidió dicho ecosistema favoreció el predominio de modelos de negocio caracterizados por la contratación predatoria de unos prestadores de servicios carentes de demanda en el mercado de trabajo tradicional. Ante esta tesitura, no es de extrañar que las plataformas digitales hayan contenido ofertas de empleo eminentemente subordinado que, a menudo, pretendían huir de la disciplina labo-

84. Vid. SCHOLZ, T., Uberworked and underpaid. How workers are disrupting the digital economy, Polity Press, Cambridge, 2017, p. 190.

85. Vid. GAGLIARDI, D. et al., op. cit., p. 124. 
ral. Dicho esto, conviene no desaprovechar la ocasión de acudir a una base tecnológica cuyas características casan bien con el paradigma cooperativo. La libre adhesión a través de entornos digitales abiertos y accesibles, la gestión democrática mediante el diseño y aplicación de algoritmos por los propios socios o la autonomía que brinda el registro de cualesquiera actos gracias a sistemas distribuidos y auto gestionados basados en la cadena de bloques constituyen tres aspectos clave que permiten vaticinar un futuro próspero al cooperativismo dentro de la economía de plataformas.

Aunque la cooperativa de trabajo asociado parezca la figura idónea a través de la cual vehicular tales iniciativas, su actividad no puede restringirse a la mera puesta a disposición de sus socios a otras empresas. Dicha práctica, constitutiva de una cesión ilegal de trabajadores, resulta tanto más grave cuanto se realiza bajo el amparo de una entidad perteneciente a la economía social, cuya actividad se presume no sólo conforme a derecho, sino incluso beneficiosa para sus miembros y para la comunidad que la acoge. $\mathrm{O}$ cuando, sin llegar incurrir en el prestamismo ilegal de trabajadores, camufla la pura y simple prestación de trabajo autónomo al abrigo de una entidad a través de la cual sus miembros facturan sus servicios. La definición jurisprudencial de lo que ha de considerarse una verdadera cooperativa de trabajo asociado arroja luz sobre un fenómeno cuyo impulso compete a los poderes públicos. Además de poner coto a su uso espurio, interesa a aquéllos impulsar un cooperativismo de plataformas que constituya una alternativa económicamente competitiva y socialmente responsable a las que hasta ahora han colonizado la economía de plataformas. Para ello, nada mejor que hacer hincapié en la formación de unos egresados que, a su vez, deben recibir de ellos el apoyo técnico preciso para abrirse camino en este nuevo entorno. 


\section{Bibliografía}

ALEMÁN PÁEZ, F.: "El derecho a la desconexión digital. Una aproximación conceptual, crítica y contextualizadora al hilo de la 'Loi Travail n. ${ }^{\circ}$ 2016-1088'", consultado en la base de datos de La Ley, no 52/2017, pp. 12-33.

ALOISI, A.: "Commoditized workers: Case study research on labour law issues arising from a set of 'on-demand/gig economy' platforms", Comparative Labor Law\&Policy Journal, no 3, 2016, pp. 653-689. DOI: https://dx.doi.org/10.2139/ ssrn.2637485

ALONSO OLEA, M.: "Trabajos familiares y amistosos, benévolos y de buena vecindad [art. 1.3.d) y e)]", Civitas. Revista española de derecho del trabajo, n. ${ }^{\circ}$ 100(1), 2000, pp. 83-90.

ARRIETA IDIAKEZ, F.J.: "La colaboración público-privada en el fomento de la economía colaborativa en el ámbito local: Una alternativa a la economía informal que trae causa de la falsa economía colaborativa”, Lan Harremanak, no 41, 2019, pp. 2-23. DOI: https://doi.org/10.1387/lan-harremanak.20877

ARRIETA IDIAKEZ, F.J.: "Las cooperativas digitales como cauce para el trabajo digital en el contexto de la economía colaborativa", Revista de derecho social, $\mathrm{n}^{\circ}$ 85, 2019, pp. 233-250.

BAYLOS GRAU, A.: "El acuerdo social sobre la "Ley riders", Según Antonio Baylos... Información, discusión y propuestas sobre las relaciones de trabajo y la ciudadania social, 13 marzo, 2021. Recuperado el 14 de marzo de 2021, de: https://baylos. blogspot.com/2021/03/el-acuerdo-social-sobre-la-ley-riders.html

BAYÓN CHACÓN, G.: "El intercambio de servicios", Revista Española de Derecho del Trabajo, no 21, 1957, pp. 33-37.

CARPIO GÁlVEZ, I. \& MONTES RUIZ, C.: "Economía colaborativa", $R A$ \& DEM: Revista de Administración y Dirección de empresas, no 4, 2020, pp. 54-71.

CHARLES, J., FERRERAS, I. \& LAMINE, A.: "A freelancers' cooperative as a case of democratic institutional experimentation for better work: a case study of SMart-Belgium", Transfer: European Review of Labour and research, vol. 26(2), pp. 157-174. DOI: https://doi.org/10.1177/1024258920919686

FAJARDO GARCÍA, I.G.: "Naturaleza jurídica de la realización entre la cooperativa de trabajo asociado y el socio-trabajador". En: Cooperativa de trabajo asociado y estatuto jurídico de sus socios trabajadores (dir. FAJARDO GARCÍA, I.G. \& coord. SENENT VIDAL, M.J.), Tirant lo Blanch, València, 2016, pp. 229-264. 
FERREIRO REGUEIRO, C.: "El régimen jurídico del trabajo autónomo económicamente dependiente", Estudios de derecho judicial, no 146, 2007, pp. 97-166. FOUCAULT, M.: Vigilar y castigar: nacimiento de la prisión, Siglo XXI Editores, Madrid, 2018.

GAGLIARDI, D., PSARRA, F., WINTJES, R., TRENDAFILI, K., PINEDA MENDOZA, J., HAALAND, K., TURKELI, S., GIOTITSAS, C., PAZAITIS, A. \& NIGLIA, F., New Technologies and Digitisation: Opportunities and Challenges for the Social Economy and Social Enterprises, European Commission, Executive Agency for SMEs, 2020. DOI: https://doi.org/10.2826/667682

GARCÍA JIMÉNEZ, M.: "Falsas cooperativas, usos abusivos y derechos de los trabajadores. Análisis jurisprudencial y propuestas de actuación”, CIRIEC-España. Revista Jurídica de Economía Social y Cooperativa, no 33, 2018, pp. 185-222.

GÓMEZ-ÁLVAREZ DÍAZ, R. \& MORALES SÁNCHEZ, R.: "Principios ontológicos de la economía colaborativa verdadera". En: Economía Colaborativa ... ¿De Verdad? (dir. GÓMEZ-ÁlVAREZ, R., PATIÑO RODRÍGUEZ, D. \& coord. PLAZA ANGULO, J.J.), Laborum, Madrid, 2018, pp. 15-42. HANDLE: https://hdl.handle.net/11441/83089

GUTIÉRREZ BENGOECHEA, M. \& SÁNCHEZ-ARCHIDONA HIDALGO, G.: Aspectos tributarios de las cooperativas y sociedades laborales, Editorial Comares, Granada, 2006.

LACOMBA PÉREZ, F.: “El dudoso fenómeno de las cooperativas 'online' de trabajo asociado o cooperativas de facturación”, Lex Social: Revista de derechos sociales, vol. 7(2), 2017, pp. 272-285.

MARTÍN VALVERDE, A., RODRÍGUEZ-SAÑUDO GUTIÉRREZ, F. \& GARCÍA MURCIA, J.: Derecho del Trabajo, Editorial Tecnos, Madrid, 2020.

MARTÍNEZ CASTAÑO, R.: "Blockchain: introducción técnica". En: 4.a Revolución industrial: impacto de la automatización y la inteligencia artificial en la sociedad y la economía digital (dirs. GARCÍA NOVOA, C. \& SANTIAGO IGLESIAS, D.), Thomson Reuters-Aranzadi, Cizur Menor, 2018, pp. 295-311.

MOLERO MANGLANO, C.: "La configuración legal del autónomo dependiente: problemas y viabilidad (Un estudio del artículo 11 de la Ley 20/2007)”, Actualidad Laboral, no 2, 2008, pp. 132-147.

RIVERA, J. DE, GORDO LÓPEZ, A.J. \& CASSIDY, P.R.: "La economía colaborativa en la era del capitalismo digital", Redes.com: revista de estudios para el desarrollo social de la Comunicación, no. 15, 2017, pp. 20-31.

DOI: https://doi.org/10.15213/redes.n15.p22 
RODRÍGUEZ FERNÁNDEZ, M.L.: "Plataformas, microworkers y otros retos del trabajo en la era digital", Futuro del Trabajo: Trabajo decente para todos, mes 3 (marzo), 2017, pp. 1-12.

SÁNCHEZ-URÁN AZANAA, Y.: “Traductores e intérpretes judiciales y jurados. Existencia de relación contractual asalariada en una empresa que utiliza aplicación informática. Comentario a la STS de 16 de noviembre de 2017”, Revista de Trabajo y Seguridad Social, 2017. Recuperado el 20 de marzo de 2021, de: https:// eprints.ucm.es/id/eprint/46608/

SCHOLZ, T.: Cooperativismo de plataforma. Desafiando la economía colaborativa corporativa, Dimmons, Barcelona, 2016.

SCHOLZ, T.: Uberworked and underpaid: How workers are disrupting the digital economy, Polity Press, Cambridge, 2017.

TODOLÍ SIGNES, A.: "El impacto de la 'Uber economy' en las relaciones laborales: los efectos de las plataformas virtuales en el contrato de trabajo", IUS Labor, $\mathrm{n}^{\circ}$ 3, 2015, pp. 1-25.

TODOLÍ SIGNES, A.: "La jurisprudencia del Tribunal Supremo en materia de falsas cooperativas". En: La promoción del emprendimiento y la inserción social desde la economía social (coord. FAJARDO GARCÍA, I.G.), CIRIEC-España, València, 2018, pp. 87-92.

TODOLÍ SIGNES, A.: "Los retos del Derecho del trabajo ante la irrupción de la Economía de plataformas digitales", El Cronista del Estado Social y Democrático de Derecho, n. ${ }^{\circ}$ 75, 2018, pp. 44-51.

VILLALBA SÁNCHEZ, A.: "Economía colaborativa, trabajo y cooperativismo de plataformas: la incidencia del punto de encuentro en la calificación del vínculo jurídico del prestador de servicios". En: Digitalización, inteligencia artificial y economía circular (dir. GARCÍA NOVOA, C., VIVEL BÚA, M. y coord. TORRES CARLOS, M. \& LADO SESTAYO, R.), Thomson Reuters-Aranzadi, Cizur Menor, 2021, pp. 141-171.

VILLALBA SÁNCHEZ, A.: "Los mecanismos de control del contrato de trabajo ante los procesos de contratación automatizada". En: Congreso Interuniversitario OIT sobre el futuro del trabajo (comps. CARRERAS GARCIA, J., HABOBA, S. \& LOBATO, J.), Vol. II, Ministerio de Trabajo y Economía Social Madrid, 2021, pp. 435-447. 